\title{
Olmesartan/amlodipine vs olmesartan/ hydrochlorothiazide in hypertensive patients with metabolic syndrome: the OLAS study
}

\author{
FJ Martinez-Martin ${ }^{1}$, H Rodriguez-Rosas², I Peiro-Martinez ${ }^{3}$, P Soriano-Perera ${ }^{4}$, \\ P Pedrianes-Martin ${ }^{2}$ and C Comi-Diaz ${ }^{2}$ \\ ${ }^{1}$ Outpatient Hypertension Clinic, Hospital Universitario Dr. Negrin, Barranco de la Ballena, Las Palmas de \\ Gran Canaria, Spain; ${ }^{2}$ Endocrinology and Nutrition Department, Hospital Universitario Dr. Negrin, Barranco \\ de la Ballena, Las Palmas de Gran Canaria, Spain; ${ }^{3}$ Servei d'Endocrinologia i Nutrició, Hospital Universitari \\ de Bellvitge, Fexia Long sn, Barcelona, Spain and ${ }^{4}$ Endocrinology Department, Hospital Universitario de \\ Canarias Carretera Cuesta Taco, San Cristobal De La Laguna (Tenerife), Spain
}

\begin{abstract}
We studied the effects of treatment with olmesartan/ amlodipine and olmesartan/hydrochlorothiazide on inflammatory and metabolic parameters (including new-onset diabetes as a secondary endpoint) in nondiabetic hypertensive patients with metabolic syndrome (MetS). A total of 120 patients with MetS and stage I and II hypertension were randomized to olmesartan $20 \mathrm{mg}$ /amlodipine $5 \mathrm{mg}$ or olmesartan $20 \mathrm{mg} / \mathrm{hydrochlor}$ othiazide $12.5 \mathrm{mg}$. If target systolic blood pressure $(<140 \mathrm{~mm} \mathrm{Hg}$ ) was not reached, doses were doubled after 13 weeks; doxazosin $4 \mathrm{mg}$ was added after 26 weeks, and doubled after 39 weeks; follow-up ended at 78 weeks. At each visit, blood pressure (BP), fasting plasma glucose, insulin, adiponectin, tumour necrosis factor- $\alpha, \mathrm{C}$-reactive protein (CRP), intercellular adhesion molecule-1, vascular cell adhesion molecule-1, interleu-
\end{abstract}

kins-1 $\beta,-6$ and -8 , and albuminuria were measured; BP was similarly reduced in both groups; $80 \%$ of patients reached target BP. Reductions in albuminuria were also similar $(50 \%)$. Only olmesartan/amlodipine reduced the insulin resistance index $(24 \%, P<0.01)$, increased plasma adiponectin $(16 \%, P<0.05)$ and significantly reduced all of the inflammation markers studied, except CRP, which showed a similar reduction in each group. The risk of new-onset diabetes was significantly lower with olmesartan/amlodipine $(P=0.02)$. Both olmesartan-based combinations were effective, but the amlodipine combination resulted in metabolic and anti-inflammatory effects that may have advantages over the hydrochlorothiazide combination.

Journal of Human Hypertension (2011) 25, 346-353; doi:10.1038/jhh.2010.104; published online 25 November 2010

Keywords: metabolic syndrome; olmesartan; amlodipine; hydrochlorothiazide; type 2 diabetes mellitus

\section{Introduction}

The prevalence of metabolic syndrome (MetS) in patients with essential hypertension is very high, and has been estimated as being close to $50 \% .{ }^{1}$ Hypertensive patients with MetS have a much higher cardiovascular (CV) risk than their counterparts without MetS, ${ }^{2}$ and also have a particularly high risk of developing type 2 diabetes mellitus (T2DM). ${ }^{3}$ In addition, the choice of antihypertensive therapy can have a large impact on the risk of development of T2DM. ${ }^{4}$ Renin-angiotensin system

Correspondence: Dr FJ Martinez-Martin, Outpatient Hypertension Clinic, Hospital Universitario Dr. Negrin, Barranco de la Ballena, Las Palmas de Gran Canaria 35020, Spain.

E-mail: dr.j.martinez@gmail.com

Received 24 April 2010; revised 28 September 2010; accepted 25 October 2010; published online 25 November 2010 blockers, that is, angiotensin-converting enzyme inhibitors and angiotensin receptor blockers (ARBs), improve insulin sensitivity and reduce the risk of developing T2DM compared with placebo, whereas calcium channel blockers (CCBs) have a neutral effect. Thiazide diuretics and $\beta$-blockers decrease insulin sensitivity and increase the incidence of T2DM. ${ }^{4}$ Therefore, the combination of an ARB and a CCB might be particularly beneficial in patients with high metabolic risk. ${ }^{5}$

The present European Guidelines for the Management of Hypertension acknowledge that most highrisk hypertensive patients require a combination of antihypertensive drugs. ${ }^{6}$ For patients with MetS, the recommended combinations are renin-angiotensin system blockers combined with low-dose thiazide diuretics or CCBs. ${ }^{6}$ In spite of the well-known effect of antihypertensive treatment on glucose and lipid metabolism, few studies have been conducted 
specifically in hypertensive patients with MetS. ${ }^{7,8}$ In addition to decreased insulin sensitivity, a low circulating level of adiponectin is a central feature of MetS and is strongly associated with the incidence of T2DM. ${ }^{9}$ High circulating levels of inflammatory markers such as tumour necrosis factor- $\alpha$ (TNF- $\alpha$ ), C-reactive protein (CRP) and interleukins-1 $\beta$ (IL-1 $\beta$ ), IL-6 and IL-8 are also a feature of MetS and increase the risk of developing T2DM. ${ }^{10}$ The adhesion molecules, intercellular adhesion molecule-1 (ICAM-1) and vascular cell adhesion molecule-1 (VCAM-1) are also strongly associated with certain features of MetS, ${ }^{11}$ particularly postprandial triglyceride and insulin levels, and may therefore be implicated in the development of atherosclerosis and T2DM. ${ }^{11}$

Olmesartan is the latest ARB to become available in clinical practice. A systematic review of the efficacy of ARBs in studies that used 24-h ambulatory blood pressure (BP) monitoring revealed that olmesartan may achieve greater ambulatory BP reductions than other ARBs, even though reductions in office BP were similar. ${ }^{12}$ Fixed-dose combinations of olmesartan with amlodipine and with hydrochlorothiazide have recently become available. In addition to other ancillary actions, amlodipine has been shown to have a modest insulin-sensitising effect that is additive to the effect of an ARB. ${ }^{13,14}$

The primary objective of this stand-alone study, OLAS (OLmesartan/Amlodipine vs olmesartan/ hydrochlorothiazide in metabolic Syndrome), was to investigate the effects of olmesartan/amlodipine and olmesartan/hydrochlorothiazide combination therapy on inflammatory (including TNF- $\alpha$, CRP, IL-1 $\beta$, -6 and -8 , ICAM-1 and VCAM-1) and metabolic parameters (including insulin sensitivity and adiponectin), with new-onset T2DM as a secondary outcome measure, in non-diabetic hypertensive patients with MetS.

\section{Methods}

The patients recruited for this study were all Europid, aged 25-75 years and had stage I and II hypertension (systolic BP (SBP) 140-179 mm Hg) and MetS, as defined by the International Diabetes Federation for Europid populations ${ }^{15}$ (waist circumference $>94 \mathrm{~cm}$ in men and $>80 \mathrm{~cm}$ in women, and at least two of the following criteria: triglycerides $>1.7 \mathrm{mmol} \mathrm{l}^{-1}$; high-density lipoprotein-cholesterol $<1.03 \mathrm{mmol} \mathrm{l}^{-1}$ in men and $<1.29 \mathrm{mmoll}^{-1}$ in women; fasting blood glucose $>5.6 \mathrm{mmoll}^{-1}$; BP $>135 / 80 \mathrm{~mm} \mathrm{Hg}$ ). Previous antihypertensive therapy, if any, was withdrawn during a washout period of 3-5 weeks before inclusion.

Patients with diabetes mellitus were excluded from the study and, in order to unmask hidden diabetes, a standard oral glucose tolerance test was performed in patients with fasting blood glucose $>5.6 \mathrm{mmol} \mathrm{l}^{-1}$. Patients were also excluded if they showed evidence of unstable angina, acute coronary syndrome, myocardial infarction, decompensated congestive heart failure, stroke or transient ischemic attack within the previous 6 months, left ventricular outflow obstruction, liver dysfunction (serum bilirubin $>1.5 \times$ or plasma aminotransferases $2 \times$ the upper normal limit), renal insufficiency (plasma creatinine $>133 \mathrm{mmol} \mathrm{l}^{-1}$ in men and $>124 \mathrm{mmoll}^{-1}$ in women) or overt proteinuria ( $>300 \mathrm{mg}$ per day). Patients with known hypersensitivity or a history of severe adverse effects with any ARB, CCB, thiazide diuretic or $\alpha$-adrenergic blocker were excluded, as well as those with any contraindication for olmesartan, amlodipine, hydrochlorothiazide or doxazosin (based on the prescribing information for each drug). Pregnant women, nursing mothers, women of childbearing potential not using adequate contraceptive methods and patients with a history of mental illness or psychiatric disorders were also excluded.

The study was conducted according to standard good clinical practice guidelines and approved by the local ethics committee of participating centres. All participants provided written informed consent before inclusion.

A parallel-group, prospective, randomized, openlabel, blinded end point design (PROBE) was used, and all measurements and procedures were performed by personnel blinded to the treatment allocation. ${ }^{16}$ The study design is shown in Figure 1. After baseline measurements were taken, patients were randomized to receive olmesartan $(20 \mathrm{mg})+$ amlodipine (5 mg) daily (OA group), or olmesartan (20 mg) + hydrochlorothiazide (12.5 mg) daily $(\mathrm{OH}$ group). After $13 \pm 2,26 \pm 2,39 \pm 2$ and $78 \pm 2$ weeks (approximately 3, 6, 9 and 18 months) all measurements were repeated. Those patients not reaching the SBP target $(<140 \mathrm{~mm} \mathrm{Hg})$ were successively uptitrated to a double dose of the initial treatment after 13 weeks, an additional $4 \mathrm{mg}$ of doxazosin (long-acting formulation) after 26 weeks, and $8 \mathrm{mg}$ of doxazosin after week 39. Additional visits were performed after $52 \pm 2$ and $65 \pm 2$ weeks (12 and 15 months) but only BP, fasting blood glucose, compliance and tolerance data were obtained.

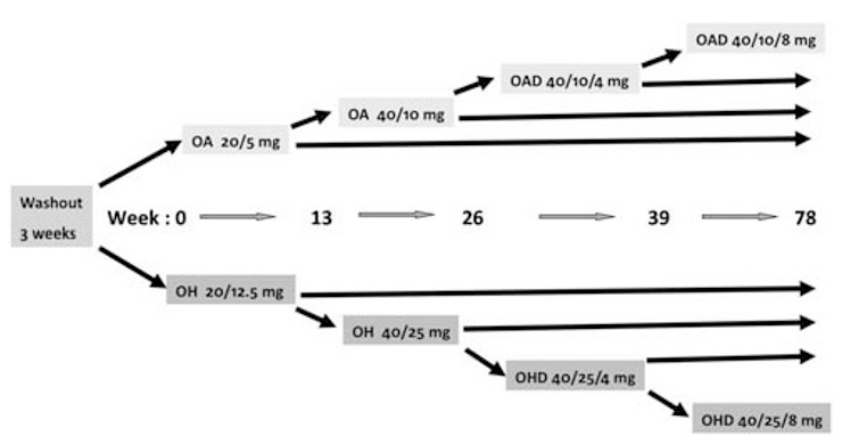

Figure 1 Design of the OLAS study showing the antihypertensive treatment schedule. The treatment was uptitrated if the target systolic blood pressure $(<140 \mathrm{~mm} \mathrm{Hg})$ had not been reached. A, amlodipine; D, doxazosin; H: hydrochlorothiazide; O, olmesartan. 
Patients who had already been uptitrated to the maximum treatment doses but still had SBP $>160 \mathrm{~mm} \mathrm{Hg}$ were removed from the study. In all patients with fasting glycaemia $>5.6 \mathrm{mmoll}^{-1}$ but $<7 \mathrm{mmoll}^{-1}$ at any visit after the first, a standard oral glucose tolerance test was performed within the following 10 days. New-onset T2DM was diagnosed in patients with fasting glycaemia $\geqslant 7 \mathrm{mmol}^{-1}$ or 120 min post-load glycaemia $>11.1 \mathrm{mmol} \mathrm{l}^{-1}$, in the absence of clinical signs of type 1 or secondary diabetes mellitus, according to the current World Health Organization guidelines. ${ }^{17}$

Weight, height, waist circumference, fasting plasma glucose and insulin, lipid profile (that is, total cholesterol, high-density lipoprotein-cholesterol and triglycerides), creatinine, sodium, potassium, bilirubin, aminotransferases, high-sensitivity-CRP, and urinary albumin and creatinine (in early morning samples) were measured by standard clinical procedures. Heart rate and BP were measured according to current guidelines, ${ }^{6}$ using a validated semi-automatic device (OMRON 705P), in the morning (between 08:30 and 11:30) after 5 min of rest in a sitting position with the back supported; patients were advised to avoid smoking and caffeinated drinks $30 \mathrm{~min}$ before the measurement. The values for BP and heart rate obtained at each visit were the average of two measurements separated by at least $2 \mathrm{~min}$; a third reading was obtained if there was a difference of $5 \mathrm{~mm} \mathrm{Hg}$ or 5 beats per minute between the two readings.

Plasma TNF- $\alpha$ was measured using a commercial enzyme-linked immunosorbent assay (ARCUS Biologicals, Modena, Italy); plasma adiponectin, ICAM1 , VCAM-1 and interleukins- $1 \beta,-6$ and -8 were also measured with a commercial enzyme-linked immunosorbent assay (LINCO Research Inc., MO, USA). The insulin resistance index (IRI) was estimated by the homeostasis model assessment formula: ${ }^{18}$ IRI $=$ fasting plasma insulin $\times$ fasting plasma glucose/ 135, with insulin in pmoll $^{-1}(1 \mathrm{mU}$ per $\mathrm{l}=$ $6.00 \mathrm{pmoll}^{-1}$ ) and glucose in $\mathrm{mmol}^{-1}$. Compliance was assessed by returned pill counts and tolerance by questionnaire.

An intention-to-treat analysis was performed in all patients who received at least one dose of study medication and had a subsequent efficacy observation. All analyses were specified a priori, except where otherwise indicated. All calculations were performed using the statistical software SPSS 15.0 (SPSS Inc., Chicago, IL, USA) for Microsoft Windows, including logistic regression modelling. The sample size was calculated with the assumption (based on a pilot trial) of a $25 \%$ difference in the means between the groups for most of the main variables (namely IRI, adiponectin, TNF- $\alpha$, IL-1 $\beta$, IL-6, ICAM-1, and VCAM-1), and a $40 \%$ variation coefficient within the groups, yielding 54 patients per group for a $90 \%$ statistical power with $\alpha=0.05$. Assuming a $10 \%$ patient loss, a sample size of 60 per group was required. However, the study could be underpowered for the secondary objective (newonset T2DM), as we did not have enough information to calculate an adequate sample size.

The data are presented as mean \pm s.d., with $95 \%$ confidence intervals for differences as appropriate. Changes from baseline and between groups in BP, heart rate and laboratory parameters were evaluated using a Student's $t$-test for paired or unpaired data, or analysis of variance, as appropriate. Categorical variables were compared using the $\chi^{2}$ or the Fisher's exact tests, as appropriate. The survival analysis for new-onset T2DM was performed using the Kaplan-Meier model followed by the log-rank test. The standard Pearson model was used for correlation analysis. All statistical tests were two-tailed and a $P$-value of $<0.05$ was considered statistically significant.

\section{Results}

Enrolment for this trial began in May 2005, including a 6-month, 8-patient pilot trial to check for feasibility and to confirm the sample size calculation. A total of 256 patients were screened, of whom 120 were randomized. At baseline, the mean age was $59.3 \pm 8.1$ years, $55 \%$ of patients were female, and the mean body mass index was $31.2 \pm 3.7 \mathrm{~kg} \mathrm{~m}^{-2}$. There were 60 patients in each group. The flowchart of the study is shown in Figure 2.

Of the 120 patients randomized, $31(25.8 \%)$ had received previous antihypertensive treatment; 17 in the OA group and 14 in the $\mathrm{OH}$ group. None had received combination treatment and all had a SBP $>140 \mathrm{~mm} \mathrm{Hg}$; three had received a thiazide diuretic, two a $\beta$-blocker, nine a CCB (seven dihydropyridinic, two non-dihydropyridinic), nine an angiotensin-converting enzyme inhibitor, seven an ARB and

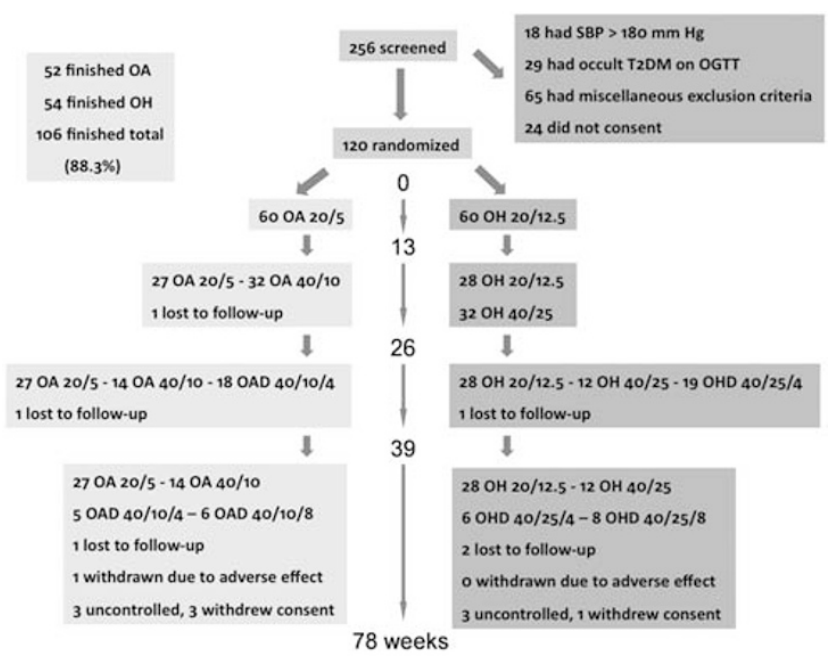

Figure 2 Flowchart of the OLAS study. Doses are mg per day. A, amlodipine; D, doxazosin; $\mathrm{H}$, hydrochlorothiazide; O, olmesartan; OGTT, oral glucose tolerance test; SBP, systolic blood pressure; T2DM, type 2 diabetes mellitus. 
one a direct renin inhibitor. A post hoc $\chi^{2}$-test showed that these drugs were evenly distributed between the groups.

BP decreased significantly in each group vs baseline $(P<0.001)$, but there were no significant differences in BP control between the groups (analysis of variance, $P=0.39$ ). Figure 3 shows the $\mathrm{BP}$ values obtained during the study. The final $\mathrm{SBP}$ values were $126.5 \pm 9.0$ and $129.9 \pm 10.9 \mathrm{~mm} \mathrm{Hg}$ for the $\mathrm{OA}$ and $\mathrm{OH}$ groups, respectively, and the final diastolic BP values were $84.9 \pm 7.3$ and $86.3 \pm 8.6 \mathrm{~mm} \mathrm{Hg}$. The mean differences between groups throughout the study were $1.5 \mathrm{~mm} \mathrm{Hg}$ for SBP $(-1.4$ to 4.4$)$ and $0.8 \mathrm{~mm} \mathrm{Hg}$ for diastolic BP $(-1.8$ to 3.6$)$. In the OA group, $53.3 \%$ of patients required doubling of the initial drug doses, and $30.0 \%$ required the addition of doxazosin. The respective figures for the $\mathrm{OH}$ group were 53.3 and $31.7 \%$. By week 26 , before the addition of doxazo$\sin , 68.3 \%$ of patients in the OA group and $66.7 \%$ in the $\mathrm{OH}$ group had reached the target $\mathrm{BP}$; at the end of the study, the respective figures were 81.7 and $78.3 \%$.

The baseline values for all of the quantitative variables in both groups are presented in Table 1 . There were no significant differences between groups at baseline. For body mass index, waist circumference, fasting plasma glucose, sodium, potassium, creatinine, lipid profile, bilirubin and aminotransferases, no differences between the treatment groups were found throughout the study; the final values are presented in Table 2 .

The albumin excretion rate decreased significantly in both groups $(P<0.01)$, with no betweengroup differences. In the OA group, the percentage reductions were $34.1 \%$ at week 26 and $50.0 \%$ at week 78; in the $\mathrm{OH}$ group, the reductions were 36.2 and $53.7 \%$, respectively. The $95 \%$ confidence intervals for the differences were, respectively, -7.5 to $11.8 \%$ and -5.9 to $13.4 \%$. The IRI and plasma fasting insulin were significantly reduced in the

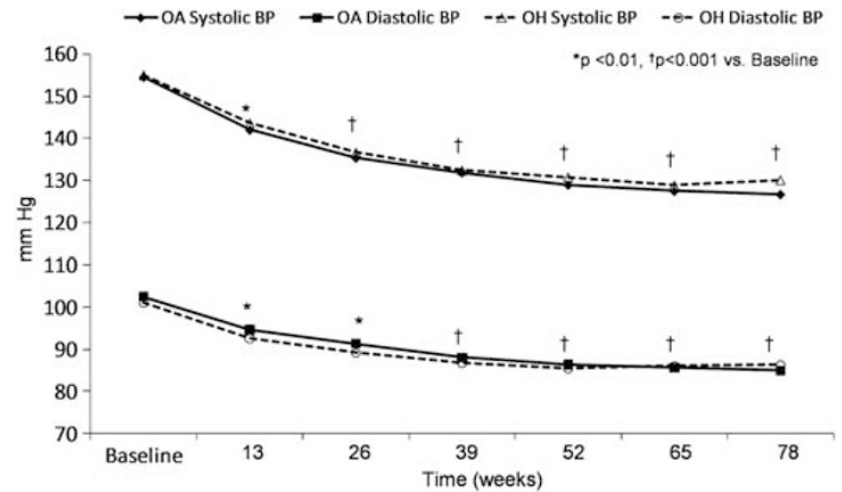

Figure 3 Systolic and diastolic blood pressures during the OLAS study. Those patients who did not achieve systolic blood pressure target $(<140 \mathrm{mmHg})$ received $4 \mathrm{mg}$ of doxazosin at week 26 , which was doubled to $8 \mathrm{mg}$ of doxazosin at week 39 if required. OA, olmesartan/amlodipine; BP, blood pressure; $\mathrm{OH}$, olmesartan/ hydrochlorothiazide.
OA group (by 24.1 and $25.0 \%$, respectively, both $P<0.01$ ), whereas adiponectin was increased by $16.3 \%(P<0.01)$. In the $\mathrm{OH}$ group, changes in IRI, plasma fasting insulin and adiponectin were not

Table 1 Baseline values for all of the quantitative variables in both groups

\begin{tabular}{|c|c|c|}
\hline Variable & OA group & $\mathrm{OH}$ group \\
\hline Age (year) & $59.0 \pm 7.9$ & $59.5 \pm 8.0$ \\
\hline Sex (\% female) & 56.7 & 53.3 \\
\hline Body mass index $\left(\mathrm{kg} \mathrm{m}^{-2}\right)$ & $31.4 \pm 3.8$ & $31.1 \pm 4.0$ \\
\hline Waist circumference (cm) & $106.1 \pm 12.9$ & $106.5 \pm 11.8$ \\
\hline SBP (mm Hg) & $154.5 \pm 10.9$ & $154.9 \pm 9.8$ \\
\hline DBP (mm Hg) & $102.5 \pm 7.9$ & $101.0 \pm 8.3$ \\
\hline Fasting glucose $\left(\mathrm{mmoll}^{-1}\right)$ & $5.52 \pm 0.71$ & $5.49 \pm 0.66$ \\
\hline Plasma $\mathrm{Na}^{+}\left(\mathrm{mEq}^{-1}\right)$ & $138 \pm 2.7$ & $139 \pm 3.2$ \\
\hline Plasma $\mathrm{K}^{+}\left(\mathrm{mEq} \mathrm{l}^{-1}\right)$ & $4.6 \pm 0.7$ & $4.5 \pm 0.8$ \\
\hline Plasma creatinine $\left(\mathrm{mmol} \mathrm{l}^{-1}\right)$ & $0.09 \pm 0.01$ & $0.09 \pm 0.02$ \\
\hline Total cholesterol $\left(\mathrm{mmol} \mathrm{l}^{-1}\right)$ & $5.27 \pm 1.12$ & $5.25 \pm 1.02$ \\
\hline HDL-cholesterol $\left(\mathrm{mmol} \mathrm{l}^{-1}\right)$ & $0.99 \pm 0.36$ & $1.04 \pm 0.39$ \\
\hline Triglycerides $\left(\mathrm{mmol} \mathrm{l}^{-1}\right)$ & $1.93 \pm 0.83$ & $1.96 \pm 0.99$ \\
\hline Total bilirubin $\left(\mathrm{mmol} \mathrm{l}^{-1}\right)$ & $12.3 \pm 2.6$ & $12.6 \pm 4.2$ \\
\hline AST (IU per l) & $38.3 \pm 7.1$ & $37.5 \pm 8.4$ \\
\hline ALT (IU per l) & $35.9 \pm 6.2$ & $32.6 \pm 7.4$ \\
\hline Albumin/creatinine $\left(\mathrm{mg} \mathrm{mmol}^{-1}\right)$ & $3.24 \pm 3.04$ & $2.91 \pm 3.18$ \\
\hline Fasting insulin $\left(\mathrm{pmol} \mathrm{l}^{-1}\right)$ & $83.70 \pm 40.26$ & $83.22 \pm 33.42$ \\
\hline IRI-HOMA (arbitrary units) & $3.41 \pm 1.1$ & $3.39 \pm 0.94$ \\
\hline Adiponectin $\left(\mu \mathrm{g} \mathrm{ml}^{-1}\right)$ & $10.71 \pm 6.31$ & $10.59 \pm 5.44$ \\
\hline TNF- $\alpha\left(\mathrm{pg} \mathrm{ml}^{-1}\right)$ & $4.25 \pm 2.16$ & $4.31 \pm 1.97$ \\
\hline CRP (mg l-1) & $2.15 \pm 0.60$ & $2.2 \pm 0.51$ \\
\hline IL-1 $\beta\left(\mathrm{pg} \mathrm{ml}^{-1}\right)$ & $0.54 \pm 0.21$ & $0.53 \pm 0.24$ \\
\hline IL-6 $\left(\mathrm{pg} \mathrm{ml}^{-1}\right)$ & $3.48 \pm 2.11$ & $3.46+1.68$ \\
\hline IL-8 $\left(\mathrm{pg} \mathrm{ml}^{-1}\right)$ & $14.42 \pm 6.31$ & $14.77 \pm 5.89$ \\
\hline ICAM-1 (ng ml-1) & $298 \pm 58$ & $303 \pm 49$ \\
\hline VCAM-1 $\left(\mathrm{ng} \mathrm{ml}^{-1}\right)$ & $857 \pm 321$ & $819 \pm 297$ \\
\hline
\end{tabular}

Abbreviations: ALT, alanine aminotransferase; AST, aspartate aminotransferase; BP, blood pressure; CRP, C-reactive protein; DBP, diastolic blood pressure; HDL, high-density lipoprotein; HOMA, homeostasis model assessment; ICAM, intercellular adhesion molecule; IL, interleukin; IRI, insulin resistance index; OA, olmesartan/amlodipine; OH, olmesartan/hydrochlorothiazide; SBP, systolic blood pressure; TNF, tumour necrosis factor; VCAM, vascular cell adhesion molecule.

There were no significant differences between groups for any of the variables.

Table 2 Final values (week 78) for the quantitative variables that did not change significantly in both groups

\begin{tabular}{|c|c|c|}
\hline Variable & OA group & OH group \\
\hline Body mass index $\left(\mathrm{kg} \mathrm{m}^{-2}\right)$ & $31.2 \pm 3.9$ & $31.6 \pm 3.7$ \\
\hline Waist circumference (cm) & $105.5 \pm 11.77$ & $107.1 \pm 9.9$ \\
\hline Fasting glucose $\left(\mathrm{mmoll}^{-1}\right)$ & $5.50 \pm 0.78$ & $5.57 \pm 0.80$ \\
\hline Plasma $\mathrm{Na}^{+}$(met per l) & $138 \pm 2.8$ & $138 \pm 3.6$ \\
\hline Plasma $\mathrm{K}^{+}\left(\mathrm{mEq} \mathrm{l} \mathrm{l}^{-1}\right)$ & $4.6 \pm 0.6$ & $4.4 \pm 0.7$ \\
\hline Plasma creatinine $\left(\mathrm{mmol} \mathrm{l}^{-1}\right)$ & $0.08 \pm 0.02$ & $0.09 \pm 0.01$ \\
\hline Total cholesterol $\left(\mathrm{mmol}^{-1}\right)$ & $5.22 \pm 1.23$ & $5.32 \pm 0.97$ \\
\hline HDL-cholesterol $\left(\mathrm{mmol} \mathrm{l}^{-1}\right)$ & $1.03 \pm 0.44$ & $1.01 \pm 0.50$ \\
\hline Triglycerides $\left(\mathrm{mmol} \mathrm{l}^{-1}\right)$ & $1.83 \pm 0.90$ & $2.13 \pm 1.12$ \\
\hline Total bilirubin $\left(\mathrm{mmol} \mathrm{l}^{-1}\right)$ & $11.8 \pm 3.2$ & $12.1 \pm 4.3$ \\
\hline AST (IU per l) & $37.9 \pm 6.8$ & $38.0 \pm 7.6$ \\
\hline ALT (IU per l) & $34.1 \pm 7.7$ & $33.8 \pm 10.1$ \\
\hline
\end{tabular}

Abbreviations: ALT, alanine aminotransferase; AST, aspartate aminotransferase; HDL, High-density lipoprotein; OA, olmesartan/amlodipine; $\mathrm{OH}$, olmesartan/hydrochlorothiazide. 
significant. These differences between the two groups were significant. Figure $4 \mathrm{a}$ shows the percentage changes in albuminuria, fasting insulin, IRI and adiponectin; the percentage changes in adiponectin showed an inverse correlation with the percentage changes in the IRI (Pearson's $R$ test $=-0.54, P<0.001)$.

Of the inflammation markers studied, only CRP was significantly reduced in both groups (by 16.7 and $14.1 \%$ in the $\mathrm{OA}$ and $\mathrm{OH}$ groups, respectively, both $P<0.05 ; 95 \%$ confidence intervals for the difference was -2.1 to $7.2 \%$ ), with no significant difference between the two groups. The other inflammation markers were significantly reduced in the OA group only (by $16.1 \%$ for TNF- $\alpha, 18.5 \%$ for IL-1 $\beta, 18.1 \%$ for IL-6, $12.8 \%$ for IL-8, $20.8 \%$ for ICAM-1 and $30.8 \%$ for VCAM-1); the between-group differences were significant for all of these inflammation markers. Figure $4 \mathrm{~b}$ shows the percentage changes in all of the inflammation markers studied.

A post hoc analysis was performed within each group in order to assess the effect of the addition of doxazosin (after week 26) on the studied variables.
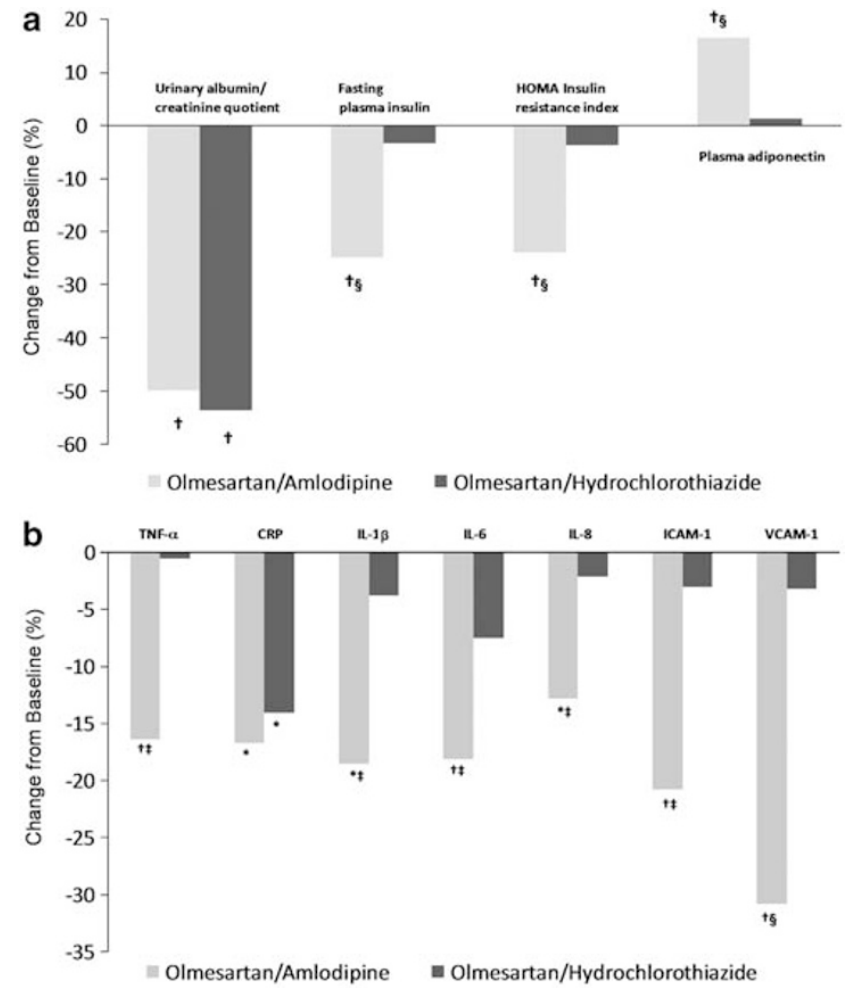

Figure 4 (a) Percentage change from baseline in urinary albumin/creatinine quotient, fasting plasma insulin, homeostasis model assessment index of insulin resistance and plasma adiponectin. (b) Percentage changes from baseline in inflammatory markers: tumour necrosis factor- $\alpha$ (TNF- $\alpha$ ), C-reactive protein

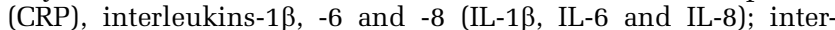
cellular adhesion molecule-1 (ICAM-1) and vascular cell adhesion molecule-1 (VCAM-1). ${ }^{*} P<0.05$ vs baseline; ${ }^{*} P<0.01$ vs baseline; ${ }^{\ddagger} P<0.05$ between groups; ${ }^{\S} P<0.01$ between groups. For simplicity, only the baseline and final values are shown, but no significant changes were observed after week 26 .
With the exception of a significant reduction in SBP and diastolic BP (similar for both groups), no differences could be found between the patients taking doxazosin and those not receiving doxazosin. After week 26, the only variables that underwent significant changes were SBP and diastolic BP (Figure 3), and new-onset T2DM (Figure 5).

During the study, three patients $(5.0 \%)$ developed T2DM in the OA group, compared with $11(18.3 \%)$ in the $\mathrm{OH}$ group (odds ratio 4.24 for $\mathrm{OA}$ vs $\mathrm{OH}$; absolute risk reduction $13.3 \%$ ). The Kaplan-Meier survival analysis is plotted in Figure 5. The log-rank test showed a significant difference between the groups $(P=0.02)$. A logistic regression modelling analysis determined that the predictors of T2DM development (after adjustement for gender and baseline values of age, body mass index, waist circumference and fasting plasma glucose) were: the IRI (OR 1.27 per 0.5 AU increment, $P=0.013$ ), $\mathrm{OH}$ treatment (OR 3.98, $P=0.023$ ) and low adiponectin (OR 2.26 per $1 \mu \mathrm{g} \mathrm{ml}^{-1}$ decrement, $P=0.043$ ). The addition of doxazosin showed no correlation with new-onset T2DM.

The compliance rate was high: $96.1 \%$ for the OA group up to week 26 and $92.7 \%$ at the end of the study; the respective figures were 94.1 and $91.8 \%$ for the $\mathrm{OH}$ group. Only one patient withdrew from the study because of side effects (malleolar oedema, in the OA group) but minor side effects were reported by low proportions of patients in the OA group (oedema $(8.3 \%)$, headache $(6.7 \%)$ and flushing or dizziness $(1.7 \%)$ ) and in the $\mathrm{OH}$ group (oedema $(3.3 \%)$, headache $(5.0 \%)$ and flushing or dizziness $(5.0 \%))$. Three patients $(5.0 \%)$ in each group were withdrawn from the study because of poor BP control, with SBP >160 $\mathrm{mm} \mathrm{Hg}$ despite full treatment. There were no differences in the incidence of side effects between the groups (Fisher's exact test). None of the patients had hypokalaemia during the study, and the correlation studies between potassium and insulin, glucose or IRI were negative (data not shown).

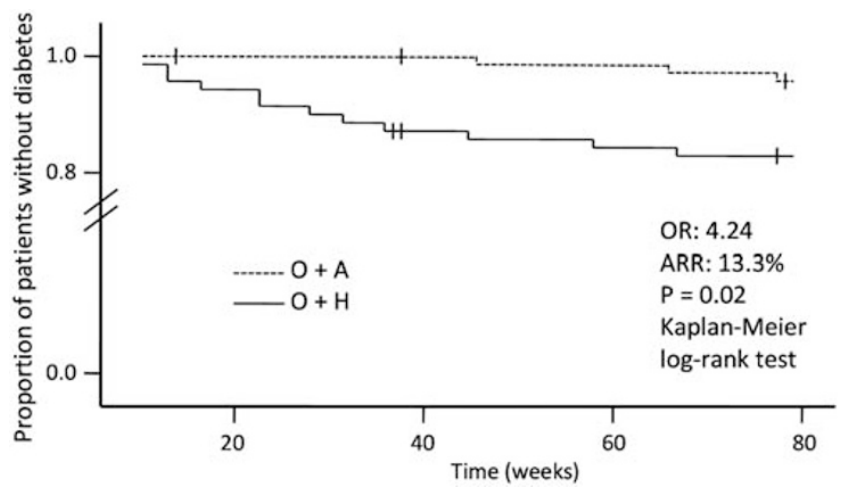

Figure 5 Kaplan-Meier survival analysis for the incidence of type 2 diabetes mellitus. A, amlodipine; ARR, absolute risk reduction; $\mathrm{H}$, hydrochlorothiazide; $\mathrm{O}$, olmesartan; $\mathrm{OR}$, odds ratio. 


\section{Discussion}

The findings of this study demonstrate that both antihypertensive combinations-olmesartan plus amlodipine and olmesartan plus hydrochlorothiazideare well tolerated and effective in non-diabetic hypertensive subjects with MetS, and allow achievement of adequate BP control in the majority of patients using a simple treatment strategy. Combination treatment has been shown to increase the efficacy of treatment and reduce adverse effects. ${ }^{19}$ A recent large meta-analysis has shown that the extra BP reduction that can be obtained with a combination of drugs from different classes is approximately five times greater than the BP reduction produced by doubling the dose of one drug. ${ }^{20}$ The olmesartan/ amlodipine combination was factorially evaluated in the COACH trial, a large, multicentre, randomized, double-blind, placebo-controlled study. ${ }^{21}$ The olmesartan/hydrochlorothiazide combination has also been extensively studied. ${ }^{22}$ Each of these olmesartan-based combinations has been found to be well tolerated and effective. However, to the best of our knowledge, neither of the combinations has been studied specifically in patients with MetS, and data on their effects in obese hypertensive patients are very scarce. Most of our patients were obese, as expected in a group with MetS; moreover, the prevalence of obesity in our community is among the highest in Europe. ${ }^{23}$ The validity of the MetS concept has been recently challenged for CV risk prediction, ${ }^{24}$ but it remains a useful predictor of T2DM development.

In the present study, significant reductions in urinary albumin/creatinine quotient were also observed in both treatment arms. Microalbuminuria is highly prevalent in non-diabetic hypertensive subjects with MetS, ${ }^{25}$ and is a well-known marker of both renal and CV risk. ${ }^{26}$ The LIFE trial, in hypertensive patients with left ventricular hypertrophy, showed that reductions in albumin excretion during treatment translate into a reduction in the risk of CV events. ${ }^{27}$

The OLAS study also shows that there are clear differences between the two olmesartan-based combinations with regard to metabolic and inflammatory markers. It has long been established that thiazide diuretics impair insulin sensitivity and increase the incidence of T2DM. ${ }^{4}$ This adverse effect can only partially be explained by hypokalaemia; a systematic review of the available evidence found that thiazides are diabetogenic even in the absence of changes in the plasma potassium level. ${ }^{28}$

Thiazide diuretics have been shown to reduce hard CV endpoints in many large controlled trials, and are recommended as first-line treatment for hypertension in the current guidelines. ${ }^{6,29}$ However, most of these trials have been based on chlorthalidone or indapamide, whereas the currently recommended low doses (up to $25 \mathrm{mg}$ per day) of hydrochlorothiazide have never been shown to reduce $\mathrm{CV}$ morbidity and mortality. ${ }^{30}$ Nevertheless, hydrochlorothiazide is, by far, the most prescribed thiazide diuretic worldwide, and the one used in almost all of the available single-pill combinations containing a diuretic.

The MEchanisms for the DIabetes preventing effect of CAndesartan (MEDICA) study found that, compared with candesartan, hydrochlorothiazide increased insulin resistance in a manner that was not related to hypokalaemia, but was associated with fat redistribution, an increase in visceral adiposity, steatohepatitis and low-grade inflammation. ${ }^{31}$ The Pharmacogenomic Evaluation of Antihypertensive Responses study found that the adverse metabolic effects (including new-onset T2DM) of hydrochlorothiazide, alone or associated with atenolol, were more frequent and severe in patients with abdominal obesity. ${ }^{32}$ The Study of Trandolapril/ Verapamil SR And Insulin Resistance (STAR), showed that in non-diabetic hypertensive patients with MetS, an angiotensin-converting enzyme inhibitor/CCB combination was associated with a much lower risk of developing diabetes than an $\mathrm{ARB} /$ hydrochlorothiazide combination, despite similar reduction in $\mathrm{BP} ;^{7}$ a correlation with potassium levels was also excluded. Our results regarding the development of T2DM are comparable, and also ruled out thiazide-induced hypokalaemia as the cause. Moreover, we were able to establish the predictive role of low adiponectin levels in this model, even independently of the changes in the insulin sensitivity index. In fact, low adiponectin is a powerful independent predictor of T2DM. ${ }^{9}$

The clinical relevance of the changes in these metabolic parameters is unknown, although a higher incidence of T2DM may not be trivial. The importance of new-onset T2DM in hypertension trials has been challenged, as it does not seem to be associated with a higher risk of mortality or clinical events in the short term, ${ }^{33}$ and for some authors its possible occurrence should not influence the selection of antihypertensive drug. ${ }^{34}$ Moreover, the STAR Long-Term Extension Trial showed that it is partially reversible. ${ }^{35}$ The risk associated with new-onset T2DM may become apparent only in very long-term studies, except in very high-risk situations. In the VALIANT trial, after an acute myocardial infarction, patients with previously known or newly diagnosed diabetes mellitus had similarly increased risks of mortality and CV events, much higher than non-diabetic patients. ${ }^{36}$

Recently, the Avoiding Cardiovascular events through COMbination therapy in Patients LIving with Systolic Hypertension (ACCOMPLISH) trial showed a $20 \%$ reduction in the risk of CV events and mortality with the use of a fixed-dose combination of benazepril/amlodipine, compared with a fixeddose combination of benazepril/hydrochlorothiazide, despite similar reduction in $\mathrm{BP} .^{37}$ These results point to an, as yet, unknown BP-independent mechanism, although a reduction in central BP may also be implied. ${ }^{38}$ Although an ARB was prescribed instead of an angiotensin-converting 
enzyme inhibitor in the OLAS study, these treatment strategies are generally similar, and our results suggest that the different effects on inflammatory mediators could contribute to the results shown in ACCOMPLISH. Blockade of the renin-angiotensin system has anti-inflammatory actions and, in particular, olmesartan has been shown to reduce CRP, TNF- $\alpha$, IL-6 and monocyte chemotactic protein-1 in the EUropean Trial on Olmesartan and Pravastatin in Inflammation and Atherosclerosis (EUTOPIA). ${ }^{39} \mathrm{Am}$ lodipine also has anti-inflammatory properties, ${ }^{13}$ whereas hydrochlorothiazide elicits microinflammation and increases the circulating levels of CRP. ${ }^{31}$ The clinical relevance of these findings is, however, not yet established.

The PROBE design may introduce investigator bias but has been validated in many hypertension trials to date, and reflects usual clinical practice more closely than a randomized controlled design. ${ }^{40}$ Another limitation of the present study is a small, not significant but consistent difference in blood pressure (1.5/0.8 $\mathrm{mm} \mathrm{Hg}$ lower in the OA group). However, a post hoc analysis did not find a significant correlation between this difference and the observed changes in metabolic and inflammation parameters.

In conclusion, both the olmesartan/amlodipine and olmesartan/hydrochlorothiazide combinations were effective and well tolerated in this study, but the effects on metabolic and inflammatory markers and on new-onset T2DM were possibly more favourable for the combination containing the CCB. The impressive results of the ACCOMPLISH trial on hard CV endpoints have not been explained, but our study may be hypothesis-generating and stimulate further research that may eventually elucidate the BP-independent protection afforded by the reninangiotensin system blocker/CCB combination.

What is known about topic

- Non-diabetic hypertensive patients with metabolic syndrome (MetS) have a higher cardiovascular risk than similar patients without MetS. They are also at high risk of developing type 2 diabetes (T2DM).

- Renin-angiotensin system (RAS) blockers, i.e. angiotensinconverting enzyme inhibitors (ACEIs) and angiotensin receptor blockers (ARBs), improve insulin sensitivity and reduce the risk of developing T2DM.

- Thiazide diuretics decrease insulin sensitivity and increase the incidence of T2DM, whereas calcium channel blockers (CCBs) have a neutral effect.

What this study adds

- This study shows that antihypertensive combination therapy with an ARB plus either amlodipine or hydrochlorothiazide is well tolerated and effective in reducing $\mathrm{BP}$ and markers of both renal and CV risk in obese non-diabetic patients with MetS.

- The study also shows that ARB + CCB combination therapy has possibly more favourable effects on metabolic and inflammatory markers and on new-onset T2DM than an ARB + hydrochlorothiazide combination in this patient population. These effects were independent of thiazideinduced hypokalaemia and BP reductions.

\section{Conflict of interest}

Francisco Javier Martinez-Martin has received lecture fees from Daiichi-Sankyo, Pfizer, Menarini, Chiesi, Takeda and others and also grant funding from Pfizer and Chiesi, but none directly related to this study. The authors have no other relevant affiliations or financial involvement with any entity with a financial interest or conflict related with the subject of this article.

\section{Acknowledgements}

The authors gratefully acknowledge the altruistic collaboration of the nurses and auxiliary personnel in our Hypertension Clinic, and also of the laboratory personnel. The authors would also like to thank Jo Bentley (inScience Communications, a Wolters Kluwer business), whose services were funded by Daiichi-Sankyo, for editing this manuscript for English language. This study was supported by a grant from the Fundación Canaria COMLP \#01501008.

\section{References}

1 Barrios V, Escobar C, Calderón A, Llisterri JL, Alegría E, Muñiz J et al. Prevalence of the metabolic syndrome in patients with hypertension treated in general practice in Spain: an assessment of blood pressure and lowdensity lipoprotein cholesterol control and accuracy of diagnosis. J Cardiometab Syndr 2007; 2: 9-15.

2 Schillaci G, Pirro M, Vaudo G, Gemelli F, Marchesi S, Porcellati C et al. Prognostic value of the metabolic syndrome in essential hypertension. J Am Coll Cardiol 2004; 43: 1817-1822.

3 Liu SJ, Guo ZR, Hu XS, Wu M, Chen FM, Kang GD et al. Risks for type-2 diabetes associated with the metabolic syndrome and the interaction between impaired fasting glucose and other components of metabolic syndrome the study from Jiangsu, China of 5 years follow-up. Diabetes Res Clin Pract 2008; 81: 117-123.

4 Elliott WJ, Meyer PM. Incident diabetes in clinical trials of antihypertensive drugs: a network metaanalysis. Lancet 2007; 369: 201-207.

5 Bakris GL. Combined therapy with a calcium channel blocker and an angiotensin II type 1 receptor blocker. J Clin Hypertens 2008; 10: 27-32.

6 Mancia G, Laurent S, Agabiti-Rosei E, Ambrosioni E, Burnier M, Caulfield MJ et al. Reappraisal of European guidelines on hypertension management: a European Society of Hypertension Task Force document. Blood Press 2009; 18: 308-347.

7 Bakris G, Molitch M, Hewkin A, Kipnes M, Sarafidis P, Fakouhi K, Bacher P, Sowers J. STAR investigators. differences in glucose tolerance between fixed-dose antihypertensive drug combinations in people with metabolic syndrome. Diabetes Care 2006; 29: 2592-2597.

8 Kintscher U, Bramlage P, Paar WD, Thoenes M, Unger T. Irbesartan for the treatment of hypertension in patients with the metabolic syndrome: a sub analysis of the Treat to Target post authorization survey. Prospective observational, two-armed study in 14200 patients. Cardiovasc Diabetol 2007; 6: 12. 
9 Heidemann C, Sun Q, van Dam RM, Meigs JB, Zhang C, Tworoger SS et al. Total and high-molecular-weight adiponectin and resistin in relation to the risk for type 2 diabetes in women. Ann Intern Med 2008; 149: 307-316.

10 Sjöholm A, Nyström T. Inflammation and the etiology of type 2 diabetes. Diabetes Metab Res Rev 2006; 22: 4-10.

11 Rubin D, Claas S, Pfeuffer M, Nothnagel M, Foelsch UR, Schrezenmeir J. s-ICAM-1 and s-VCAM1 in healthy men are strongly associated with traits of the metabolic syndrome, becoming evident in the postprandial response to a lipid-rich meal. Lipids Health Dis 2008; 7: 32.

12 Fabia MJ, Abdilla N, Oltra R, Fernandez C, Redon J. Antihypertensive activity of angiotensin II AT1 receptor antagonists: a systematic review of studies with $24 \mathrm{~h}$ ambulatory blood pressure monitoring. J Hypertens 2007; 25: 1327-1336.

13 Mason RP, Marche P, Hintze TH. Novel vascular biology of third-generation L-type calcium channel antagonists: ancillary actions of amlodipine. Arterioscler Thromb Vasc Biol 2003; 23: 2155-2163.

14 Fogari R, Preti P, Zoppi A, Mugellini A, Corradi L, Lazzari P, Santoro T, Derosa G. Effect of valsartan addition to amlodipine on insulin sensitivity in overweight-obese hypertensive patients. Intern Med 2008; 47: 1851-1857.

15 Alberti KG, Zimmet P, Shaw J. The metabolic syndrome-a new worldwide definition. Lancet 2005; 366: 1059-1062.

16 Hansson L, Hedner T, Dahlöf B. Prospective randomized open blinded end-point (PROBE) study. A novel design for intervention trials. Blood Press 1992; 1: 113-119.

17 WHO/International Diabetes Consultation. Definition and Diagnosis of Diabetes Mellitus and Intermediate Hyperglycaemia. WHO: Geneva, Switzerland, 2006, 46pp.

18 Wallace TM, Levy JC, Matthews DR. Use and abuse of HOMA modeling. Diabetes Care 2004; 27: 1487-1495.

19 Law MR, Wald NJ, Morris JK, Jordan RE. Value of low dose combination treatment with blood pressure lowering drugs: analysis of 354 randomised trials. BMJ 2003; 326: 1427-1431.

20 Wald DS, Law M, Morris JK, Bestwick JP, Wald NJ. Combination therapy versus monotherapy in reducing blood pressure: meta-analysis on 11000 participants from 42 trials. Am J Med 2009; 122: 290-300.

21 Chrysant SG, Melino M, Karki S, Lee J, Heyrman R. The combination of olmesartan medoxomil and amlodipine besylate in controlling high blood pressure: $\mathrm{COACH}$, a randomized, double-blind, placebo-controlled, 8-week factorial efficacy and safety study. Clin Ther 2008; 30: 587-604.

22 Punzi HA. Efficacy and safety of olmesartan medoxomil alone and in combination with hydrochlorothiazide. Expert Rev Cardiovasc Ther 2009; 7: 229-239.

23 De Pablos-Velasco PL, Martínez-Martín FJ, RodríguezPérez F. Prevalence of obesity in a Canarian community. Association with type 2 diabetes mellitus: the Guía Study. Eur J Clin Nutr 2002; 56: 557-560.

24 Borch-Johnsen K, Wareham N. The rise and fall of the metabolic syndrome. Diabetologia 2010; 53: 597-599.

25 Ninomiya T, Kiyohara Y. Albuminuria and chronic kidney disease in association with the metabolic syndrome. J Cardiometab Syndr 2007; 2: 104-107.

26 Gerstein HC, Mann JF, Yi Q, Zinman B, Dinneen SF, Hoogwerf B et al. Albuminuria and risk of cardiovascular events, death, and heart failure in diabetic and nondiabetic individuals. JAMA 2001; 286: 421-426.

27 Ibsen $\mathrm{H}$, Olsen $\mathrm{MH}$, Wachtell K, Borch-Johnsen K, Lindholm LH, Mogensen CE et al. Reduction in albuminuria translates to reduction in cardiovascular events in hypertensive patients: losartan intervention for endpoint reduction in hypertension study. Hypertension 2005; 45: 198-202.

28 Bakris G, Stockert J, Molitch M, Zhou Q, Champion A, Bacher $\mathrm{P}$ et al. Risk factor assessment for new onset diabetes: literature review. Diabetes Obes Metab 2009; 11: 177-187.

29 Chobanian AV, Bakris GL, Black HR, Cushman WC, Green LA, Izzo Jr JL et al. The seventh report of the Joint National Committee on prevention, detection, evaluation, and treatment of high blood pressure: the JNC 7 report. JAMA 2003; 289: 2560-2572.

30 Kaplan NM. The choice of thiazide diuretics: why chlorthalidone may replace hydrochlorothiazide. Hypertension 2009; 54: 951-953.

31 Eriksson JW, Jansson PA, Carlberg B, Hägg A, Kurland $\mathrm{L}$, Svensson MK et al. Hydrochlorothiazide, but not Candesartan, aggravates insulin resistance and causes visceral and hepatic fat accumulation: the mechanisms for the diabetes preventing effect of Candesartan (MEDICA) study. Hypertension 2008; 52: 1030-1037.

32 Cooper-DeHoff RM, Wen S, Beitelshees AL, Zineh I, Gums JG, Turner ST et al. Impact of abdominal obesity on incidence of adverse metabolic effects associated with antihypertensive medications. Hypertension 2010; 55: 61-68.

33 Alderman MH. New-onset diabetes during antihypertensive therapy. Am J Hypertens 2008; 21: 493-499.

34 Alderman MH. Is new-onset diabetes mellitus important? Yes, but... High Blood Pres \& Cardiovasc Prev 2008; 15: 5-8.

35 Bakris G, Molitch M, Zhou Q, Sarafidis P, Champion A, Bacher $\mathrm{P}$ et al. Reversal of diuretic-associated impaired glucose tolerance and new-onset diabetes: results of the STAR-LET study. J Cardiometab Syndr 2008; 3: 18-25.

36 Aguilar D, Solomon SD, Køber L, Rouleau JL, Skali H, McMurray JJ et al. Newly diagnosed and previously known diabetes mellitus and 1-year outcomes of acute myocardial infarction: the VALsartan In Acute myocardial iNfarcTion (VALIANT) trial. Circulation 2004; 110: $1572-1578$.

37 Jamerson K, Weber MA, Bakris GL, Dahlöf B, Pitt B, Shi V et al. Benazepril plus amlodipine or hydrochlorothiazide for hypertension in high-risk patients. $N$ Engl J Med 2008; 359: 2417-2428.

38 Matsui Y, Eguchi K, O'Rourke MF, Ishikawa J, Miyashita $\mathrm{H}$, Shimada $\mathrm{K}$ et al. Differential effects between a calcium channel blocker and a diuretic when used in combination with angiotensin II receptor blocker on central aortic pressure in hypertensive patients. Hypertension 2009; 54: 716-723.

39 Fliser D, Buchholz K, Haller H. Anti-inflammatory effects of angiotensin II subtype 1 receptor blockade in hypertension patients with microinflammation. Circulation 2004; 110: 1103-1107.

40 Smith DH, Neutel JM, Lacourcière Y, KempthorneRawson J. Prospective, randomized, open-label, blindedendpoint (PROBE) designed trials yield the same results as double-blind, placebo-controlled trials with respect to ABPM measurements. J Hypertens 2003; 21: 1291-1298.

This work is licensed under the Creative Commons Attribution-NonCommercialNo Derivative Works 3.0 Unported License. To view a copy of this license, visit http://creativecommons. org/licenses/by-nc-nd/3.0/ 